\title{
IPRONIAZID IN THE TREATMENT OF ANGINA OF EFFORT
}

\author{
BY
}

\author{
P. J. D. SNOW AND D. E. ANDERSON \\ From the University Departments of Medicine and Cardiology, Manchester Royal Infirmary \\ Received November 9, 1958
}

Iproniazid (a derivative of isoniazid) was originally introduced because of its antituberculous properties, but for some time it has been known to have several other effects, some of which may be due to the fact that it inhibits mono-amine oxidase, the enzyme responsible for the inactivation of serotonin (5 hydroxy-tryptamine) and adrenalin. Recently, Cesarman (1957) noted great improvement in the anginal symptoms of a patient undergoing treatment with iproniazid for a depressive state. Subsequently he tried out its effect on 41 patients with severe angina, and claimed complete relief of symptoms within twelve days of starting treatment in all of them. Cossio (1957 \& 58) also claimed improvement in 70 per cent of a similar series of patients.

Unfortunately, neither series was controlled, and before accepting these results it is important that they be confirmed by more critical study. Accordingly, a double blind trial was devised, the results of which are the subject of this paper.

Selection of Patients. Over 170 patients with angina of effort attending the Department of Cardiology were interviewed, from which a series of 52 (45 men and 7 women) were selected. All were suffering from moderate or severe angina of effort, which had not undergone any change in severity within the previous six months. Patients receiving reserpine and those suspected of being unreliable witnesses were excluded.

Method. At the initial interview, the severity of the symptoms was assessed using normal daily activities and the daily consumption of trinitrin as indices. Each patient was given a card to record his trinitrin requirements over the following three weeks, and was asked to note any side effects and the time at which improvement, if any, occurred. In the event of more than trivial side effects, patients were instructed to stop taking the tablets and report immediately.

The patient's usual treatment (peritrate, diuretics, digitalis, etc.), was continued as usual, the only alteration being the addition of the trial tablets that consisted of $50 \mathrm{mg}$. of iproniazid with a similar tablet of lactose as a control. The dose prescribed was one tablet, three times a day, i.e. $150 \mathrm{mg}$. of iproniazid. The tablets were distributed through the hospital pharmacy, neither the patients nor investigators knowing which preparation was being dispensed first. All patients were interviewed after three weeks when the tablets were changed over and again after a further three weeks when any improvement was assessed with particular attention to the relative efficacy of the two courses of tablets.

\section{RESULTS}

Of the 52 patients who were started on the trial, 11 failed to complete it. This was due to aggravation of angina in two (both on the control tablets at the time) and the onset of myocardial infarction in one: this patient was taking iproniazid but we have no reason to suppose that it was responsible. Seven patients complained of various side effects but only three of these were taking iproniazid at the time, the others receiving control tablets: the remaining patient failed to reattend and the reason could not be ascertained. The trial was completed by 41 patients and all of them could be placed in one of four groups as shown in Table I. 
Of the 17 patients who experienced some improvement with both tablets, 4 considered iproniazid slightly superior, 4 preferred the control tablet, while 9 noted no difference. In 7 of the 10 patients who were most improved while on the control tablet, iproniazid had been given first. We therefore considered the possibility that the improvement was a delayed effect of the iproniazid, but the time of improvement (either immediate or only after 10 to 14 days) made this unlikely.

TABLE I

Effect of Iproniazid in Patients with Angina

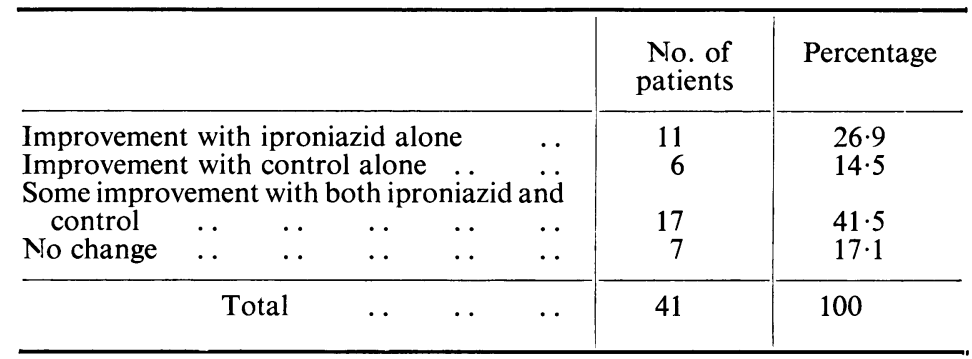

Those patients who improved with iproniazid did so between the third and seventh day, although a maximal effect was not always obtained in less than two to three weeks.

Side Effects. These were noted by 26 patients while receiving iproniazid and included most commonly constipation and dizziness, but this was accompanied by hypotension in only three patients. Other complaints included impotence, headache, insomnia, lassitude, hunger, and dyspnœa.

Six patients complained of constipation while receiving the control tablet but in each case iproniazid had been exhibited first and may have been responsible. Others complained of dizziness (4 patients), headache (2), and lassitude (1), while receiving the control tablets, but in only one instance could iproniazid have been responsible.

\section{Discussion}

The results of this double blind trial do not support the claims for the value of iproniazid in patients with angina pectoris put forward by Cesarman (1957) and by Cossio (1957).

On iproniazid alone 26 per cent of patients were improved compared with 14 per cent who were strikingly improved on the control tablet, iproniazid having no apparent effect. Most patients $(41 \%)$ were slightly improved with both the iproniazid and the control tablet, so that a total of 28 patients $(68 \%)$ improved on iproniazid compared with $23(56 \%)$ who improved on the control tablet, there being no significant difference between these figures. These results underline the importance of adequate control in assessing any treatment for angina of effort, which is notoriously liable to improve, at least temporarily, no matter what treatment is given.

Although the claims originally made for iproniazid do not seem justified, we cannot deny that it may benefit some patients. In view of the frequency of side effects, and their potential hazards, however, we would not advise its indiscriminate use, but it may be worth a trial in severely handicapped patients in whom no other form of treatment has had any beneficial effect.

We wish to thank Dr. A. Morgan Jones, Director of the Department of Cardiology, for permission to study the patients who participated in the trial, and Dr. E. G. Wade for his helpful criticism.

We also wish to thank Dr. Marks of Roche Products Ltd., for supplying both the iproniazid and control tablets, and Mr. Lloyd of the hospital pharmacy for undertaking the distribution of the tablets.

\section{REFERENCES}

Cesarman, T. (1957). Arch. Inst. Cardiol. Mex., 27, 563.

Cossio, P. (1957). Pren. méd. Argentina, 44, 2679.

_- (1958). Amer. Heart J., 56, 113. 